\title{
Species recognition by the sequence of discharge intervals in weakly electric fishes of the genus Campylomormyrus (Mormyridae, Teleostei)
}

\author{
BERND KRAMER \& BIRGIT KUHN \\ Institut für Zoologie der Universität, D-93040 Regensburg, Germany \\ (Received 2 April 1993; initial acceptance 25 June 1993; \\ final acceptance 21 July 1993; MS. number: 4353)
}

- Abstract. In two Campylomormyrus species, tamandua and rhynchophorus from Central Africa, the electric organ discharge (EOD) activity was studied during the nocturnal activity phase in the laboratory. Both species have a pulse-type EOD of less than $200 \mu$ s duration and similar waveform; the sequence of inter-discharge intervals, however, differed characteristically: C. tamandua displayed a 'micro-pattern' encompassing nearly the whole range of intervals in a sequence of only three intervals (long-intermediate-short), while in C. rhynchophorus adjacent intervals tended to be more similar in duration. Four $C$. rhynchophorus and five $C$. tamandua were tested for their preference of conspecific pulse sequences rather than those of the other species, respectively, in playback experiments. These were performed in a T-maze paradigm such that two pulse patterns, one from each species, were simultaneously presented via two electric fish dipole models. Two pulse sequences recorded from different individuals were used to represent each species; the natural EOD waveform was replaced by a square-wave pulse of approximately natural duration. The pattern pairings and the sequence of stimulus patterns followed a randomized blocks design. Each of the four C. rhynchophorus had significantly higher preference scores for the conspecific pulse patterns than for those of $C$. tamandua, while in C. tamandua no such discrimination was observed. It is suggested that the juvenile $C$. tamandua used would probably have joined mixed-species schools as reported to exist in the wild, while this appears unlikely in the more mature $C$. rhynchophorus. One of the functions of the inter-discharge interval code of communication in mormyrids is species recognition although this may be seen only in sufficiently mature fish.

Mormyrid fish use their electric organ discharges (EODs) for active electrolocation (for a review see Bastian 1990) and communication (for reviews see Moller 1980; Hopkins 1986, 1988; Kramer 1990a, b, 1994). The electric organ discharge of a mormyrid is a brief pulse repeated at usually less than 10 per $s$ (pulses/s or $\mathrm{Hz}$ ) at rest during the day, and, depending on the species, even greater than 100 pulses/s during vigorous activities such as attack.

The sequence of discharge intervals, or interval patterns, accompanying resting, locomotion, agonistic behaviour and reproduction changes characteristically in several species; this has been found both descriptively and experimentally, using playback (for a review see Kramer 1990b). The occurrence of context- as well as speciesspecific discharge interval patterns accompanying overt activities has led to the hypothesis of an inter-discharge interval code of communication as a symplesiomorphic group character (i.e. one that is primitive and shared between taxa) in the Mormyridae (Kramer 1994).

Species recognition is one of the suggested functions of the inter-discharge interval code for which there is experimental support. Thus, members of a mixed-species group of mormyrids, tested during daylight, preferred caged conspecifics to mormyrids of other species (Moller \& Serrier 1986); several sensory modalities, including the electrosensory, were probably involved (Moller et al. 1982; Teyssèdre \& Moller 1982). An exclusively electrosensory preference for the sequence of discharge intervals recorded from conspecifics rather than those from Pollimyrus isidori or Brienomyrus niger was experimentally demonstrated in Petrocephalus bovei (Lücker 1982, 1983; Kramer \& Lücker 1990). The EOD has been shown to be important for the cohesion of schooling mormyrids even when tested during the day (when many mormyrids hide) (Moller 1976); it is probably of still greater importance 
during the night when mormyrids migrate (Moller et al. 1979).

Species recognition among mormyrids has, up to now, been tested only using members of different genera where fairly large differences, including the inter-discharge interval code, may be assumed because of their phylogenetic distance. Here we report evidence for an exclusively electrosensory species recognition by the sequence of discharge intervals in members of the same genus, Campylomormyrus tamandua and C. rhynchophorus. Very little, if anything, is known about the behaviour and ecology of these fish (except a recent paper by Kramer \& Kuhn 1993).

\section{METHODS}

\section{Study Species}

The genus Campylomormyrus Bleeker 1874 comprises 14 species (Gosse 1984) all of which possess trumpet-like snouts of sometimes spectacular dimensions; among all Mormyridae, these are the true 'elephantfishes'. Their forceps- or probe-like trumpets are regarded as adaptations to specialized feeding habits within the ecological type 'bottom-oriented micropredator' (Daget \& Durand 1981). The genus is of Central African distribution with $C$. tamandua also widely occurring in West Africa (Lévêque \& Paugy 1984).

Eight C. tamandua (Günther 1864) and four C. rhynchophorus (Boulenger 1898) were obtained from a tropical fish dealer near Frankfurt/Main (Germany) who had imported the fish direct from Kinshasa (Zaïre), specifying the location of origin as an 'affluent of the Stanley Pool, $150 \mathrm{~km}$ north of Kinshasa'. The fish are not endangered and are eaten in large numbers by the local population.

The species were determined using the keys by Poll et al. (1982), Lévêque \& Paugy (1984) and Lévêque et al. (1990). Eleven morphological characters were analysed, among them the number of scales around the caudal peduncle, the number of rays of the dorsal and anal fins, the relationship between total length and snout length and the angle of inclination of the snout. Apart from the markedly different coloration, which is a chequered pattern of dark and light brown as described for juvenile $C$. tamandua (Lévêque et al. 1990), versus an almost uniform dark (almost black) in C.rhynchophorus, the most clear-cut

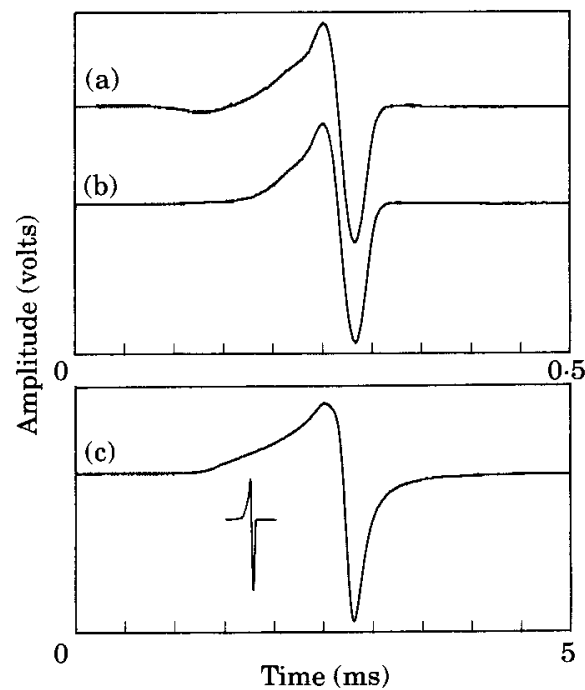

Figure 1. Waveforms of electric organ discharges, all of the pulse type, of (a) C. tamandua, (b) C. rhynchophorus, and (c) the exceptional $C$. rhynchophorus number 3 with the extremely long duration discharge. Each trace starts at zero volts; head-positive is up. For comparison, the inset of (c) shows the $C$. rhynchophorus discharge of (b) at the lower resolution time scale of (c).

morphological difference between the two species is the number of scales around the caudal peduncle: 16 in C.rhynchophorus and 12 in C. tamandua (confirmed in all our fish).

Our C. rhynchophorus were $8.9-10.0 \mathrm{~cm}$ long (standard length); the C.tamandua were of similar size $(8.6-11.8 \mathrm{~cm})$ except for one bigger fish of $14.0 \mathrm{~cm}$. Thus the C.rhynchophorus were approaching half-maximum size (maximum total length, $22 \mathrm{~cm}$; Gosse 1984) while most C. tamandua were closer to a quarter maximum size (maximum standard length, $43 \mathrm{~cm}$; Gosse 1984).

All C. tamandua had similar waveforms of their EODs (Fig. 1a): two main phases, the head-positive $\mathbf{P}$ and the head-negative $\mathrm{N}$ phase, of a mean total duration of $133 \pm 2 \mu \mathrm{s}$ (SE; $N=6$ fish), were preceded by a weak pre-potential of widely varying duration $(15-83 \mu \mathrm{s}$; at a water conductivity of $70 \mu \mathrm{S} / \mathrm{cm}$ as often encountered in tropical rivers). The discharges of all but one $C$. rhynchophorus closely resembled those of C. tamandua but for their lack of a prepotential (Fig. 1b); total mean duration of the C. rhynchophorus EOD was $140 \pm 4 \mu \mathrm{s}$ (SE; $N=3$ fish; see Kramer \& Kuhn 1993). 
One C. rhynchophorus had a deviant discharge lasting $3.3 \mathrm{~ms}$, about 20 times longer than that of its conspecifics (Fig. 1c). According to the key by Poll et al. (1982) this fish is clearly a C. rhynchophorus, in spite of a somewhat longer snout than the other three fish $(22 \mathrm{~mm}$ versus - $15-18 \mathrm{~mm})$, a snout a little less inclined relative to the body long axis $\left(40^{\circ}\right.$ versus $\left.43^{\circ}-49^{\circ}\right)$, and a somewhat larger eye. All these measures were, however, within the variability described for the species $C$. rhynchophorus (Poll et al. 1982). A similar situation (totally different EODs in fish classified as members of the same species on morphological grounds) was observed in Mormyrops curviceps (Moller \& Brown 1990).

The fish were kept in 360-litre communal aquaria at $27 \pm 1^{\circ} \mathrm{C}$ with water conductivity $100 \mu \mathrm{S} / \mathrm{cm}$ and a $12: 12 \mathrm{~h}$ light:dark cycle. The food was Chironomus larvae from a frozen supply.

\section{Recording EOD Sequences}

The fish were transferred from larger holding tanks to a recording aquarium (250 litre, $100 \times 50 \times 50 \mathrm{~cm}$ ) where they were kept isolated for at least $24 \mathrm{~h}$ before recording. The aquarium was bare except for a porous pot shelter in its centre. The walls of the aquarium were fitted with electrodes which were fine silver wires, arranged in a matrix of $20-28$ per aquarium wall surface, making only point contact with the water. Via $47-\mathrm{k} \Omega$ resistors the silver wires were connected to a single lead which was the output of one electrode matrix (see Kramer 1974). A plastic mesh cage kept the fish $5 \mathrm{~cm}$ away from the electrodes.

Opposite electrodes (i.e. two horizontal pairs normal to each other, in $X$ and $Y$ orientation) were connected to separate, differential preamplifiers (up to $1000 \times ; 10 \mathrm{~Hz}-33 \mathrm{kHz}$ ); the output of each was full-way rectified, summed and fed into a Schmitt trigger which generated $a+5 \mathrm{~V}$, $0.75 \mathrm{~ms}$ square-wave pulse for each EOD. This pulse was recorded on magnetic tape (Uher 4400 Report Monitor).

The Schmitt trigger level was continuously monitored by an oscilloscope. Before recording on magnetic tape, we made several test recordings using a Nicolet digital analyser (model 1074) in 'Time Interval Trend' mode which stored up to 4096 inter-discharge intervals; interfering noise impulses were detected by the occurrence of intervals $<9 \mathrm{~ms}$ in the Nicolet display. The Schmitt trigger level was adjusted as low as possible in order to detect all EODs (independent of the amplitude fluctuations associated with a fish's orientation relative to the electrodes), but sufficiently high in order to reject noise impulses.

A fish's discharge sequence was recorded in total darkness, that is, during its activity phase. To ensure that only EOD activity accompanying active swimming was recorded, the fish's behaviour was continuously monitored by video equipment (consisting of two infra-red light sources mounted overhead; an infra-red-sensitive videocamera, Grundig model FA $70 \mathrm{H}$; and a remote video monitor). The camera was positioned such that the aquarium was seen from its side and glass bottom (through a mirror below the aquarium inclined by $45^{\circ}$ ).

The taped sequences of discharges were analysed by the Nicolet analyser (with model SH-71 Time Frequency Analyzer module) in 'Time Interval Trend' mode with a resolution of $0.1 \mathrm{~ms}$, or in 'Time Interval Distribution' mode with a resolution of $1 \mathrm{~ms}$. The memory contents stored in the Nicolet analyser were transferred to disc and plotted under computer control.

\section{Spontaneous Choice Experiments}

The experimental aquarium (250-litre; $90 \pm 10 \mu \mathrm{S} / \mathrm{cm} ; 26 \pm 0 \cdot 5^{\circ} \mathrm{C}$ ) was bare except for a central porous pot which served as a fish's shelter, and two electric fish dipole models symmetrically placed at the far ends of the aquarium, in parallel to and $5 \mathrm{~cm}$ from the smaller sides of the aquarium (a T-maze paradigm). The dipoles were made from $0.5 \mathrm{~cm}$ carbon rods, vertically inserted in a horizontally oriented, water-tight Perspex tube which carried the leads (electrode separation, $2.1 \mathrm{~cm}$; electrode length, $0.9 \mathrm{~cm}$ ). The Perspex tubes were $5 \mathrm{~cm}$ above the aquarium bottom, and $38 \mathrm{~cm}$ from the porous pot shelter.

Stimulus intensity was adjusted to the EOD amplitude of a medium-sized fish hiding in its porous pot, measured with a pair of carbon rod electrodes separated by $49 \mathrm{~cm}$, symmetrically placed behind the fish's tail and in front of its head. At $90 \mu \mathrm{S} / \mathrm{cm}$ and $26.5^{\circ} \mathrm{C}$ the EOD peak-topeak amplitude thus measured was $40 \mathrm{mV}$. For the stimulus pulse, a monopolar square wave of $180 \mu \mathrm{s}$ and $40 \mathrm{mV}$ amplitude (from baseline to peak; i.e. peak amplitude as measured under identical conditions) was chosen; the amplitude 
Table I. Discharge activity $(\bar{X} \pm \mathrm{SE})$ during nocturnal swimming in isolated fish

\begin{tabular}{lcc}
\hline & Discharge rate $(\mathrm{Hz})$ & $\begin{array}{c}\text { Measure of } \\
\text { skewness of histograms } \\
\text { (ms, see text) }\end{array}$ \\
\hline C. rhynchophorus & $25 \cdot 88 \pm 1 \cdot 16$ & $14 \cdot 53 \pm 1 \cdot 634$ \\
$N=4$ & $N=9$ & $N=9$ \\
C. tamandua & $22 \cdot 13 \pm 0 \cdot 57$ & $30 \cdot 53 \pm 1 \cdot 24$ \\
$N=8$ & $N=23$ & $N=23$ \\
$P^{*}$ & 0.003 & $<0 \cdot 0001$ \\
\hline
\end{tabular}

Each sample comprises between 18070 and 43951 discharges. C. tamandua, $26.5 \pm 0 \cdot 5^{\circ} \mathrm{C}$;

C. rhynchophorus, $26 \pm 0 \cdot 5^{\circ} \mathrm{C}$.

*Unpaired $t$-test, two-tailed, $d f=30$.

was adjusted after the fish was replaced by a dipole.

Each dipole was connected to its own custombuilt, microprocessor-controlled stimulus generator with memory (described in Kramer \& Weymann 1987). Before each trial, these devices received one of four inter-discharge interval lists (up to 2048 intervals) via a digital interface from a computer; the computer also started the stimulation on the operator's command and stopped it automatically after $7 \mathrm{~min}$. Two of four interval lists (discharge sequences) were presented simultaneously: one $C$. rhynchophorus pattern was paired with one $C$. tamandua pattern. From both species the randomly selected discharge patterns from two individuals, recorded during their night-time swimming activity, were used in order not to depend so heavily on possible idiosyncrasies of an individual (Kroodsma 1989). There was only one individual of each 'stimulus' species in an earlier study and the EOD pulse sequences were stored on conventional magnetic tape instead of being encoded in digital form and stored on computer disc (earlier study, Kramer \& Lücker 1990).

The sequence of trials followed a randomized blocks design (Cochran \& Cox 1957); all possible pattern pairings were used except those opposing the two patterns from the same species; the sequence of the remaining four pattern combinations was randomized using Table 15.5 of random permutations of nine from Cochran \& Cox (1957). Any possible side preferences of the fish were balanced by presenting all patterns equally often on the right and on the left dipole (on a random sequence).

There were up to 12 trials per day with a minimum of $15 \mathrm{~min}$ between trials. Half of all trials were performed during the dark phase. The operator started a trial only when the experimental fish was hiding in its porous pot shelter.

Using two stopwatches we measured a fish's preference for a stimulus pattern as the time it spent within $20 \mathrm{~cm}$ of a dipole. Fish were observed by an overhead mirror inclined by $45^{\circ}$; direct vision was obscured by isolation material covering all sides of the aquarium. Attack intention movements directed at the dipole were recorded by two mechanical counters; characteristic attack sequences were videotaped (Panasonic, model AG7330) for subsequent analysis.

On the completion of a set of four trials that represented a permutation of all four pattern pairings the computer calculated a mean value for each measure; these data represented a sample size of $N=1$. After $N$ had sufficiently increased by repeating the experiments the data were analysed using Sachs (1984), Neave \& Worthington (1988) and Siegel \& Castellan (1988), as well as the statistical package 'InStat' (version 2.0, 1993).

\section{RESULTS}

\section{Inter-discharge Interval Patterns}

During their nocturnal swimming activity the mean discharge rates of both Campylomormyrus species were rather high compared with those of other mormyrid species: from $17 \cdot 3$ to $26 \cdot 7 \mathrm{pulses} / \mathrm{s}$ $(\mathrm{Hz})$ in C. tamandua, and from 20.3 to $31 \mathrm{pulses} / \mathrm{s}$ in C. rhynchophorus (for other species, see review in Kramer 1990b). The grand mean discharge rate of the C. rhynchophorus, 25.9 pulses/s, was significantly higher than that of the C.tamandua, $22 \cdot 1 \mathrm{pulses} / \mathrm{s}$ (Table I). 


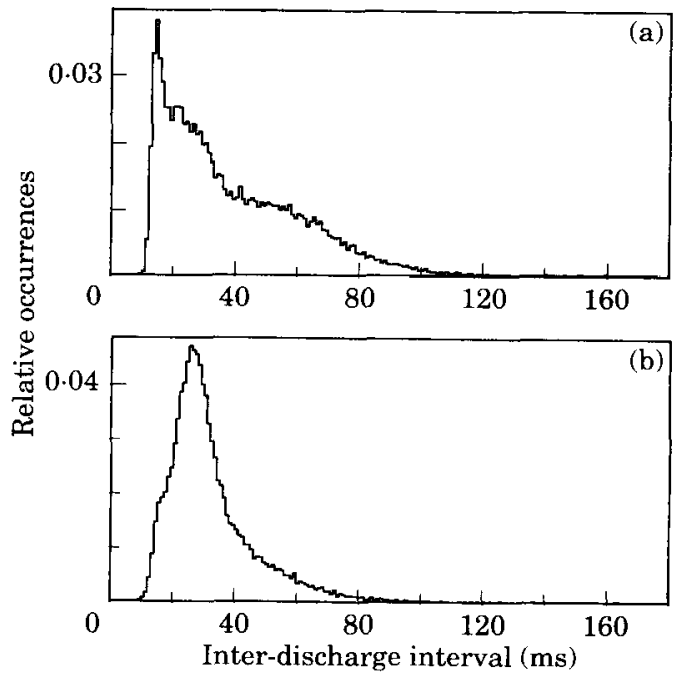

Figure 2. Histograms of inter-discharge interval distributions during nocturnal swimming in (a) C. tamandua number 1 and (b) C. rhynchophorus number 2. Number of EODs analysed: 29413 in (a) and 27276 in (b). The mean pulse rates were 25.6 and 28.8 pulses/s in (a) and (b), respectively.

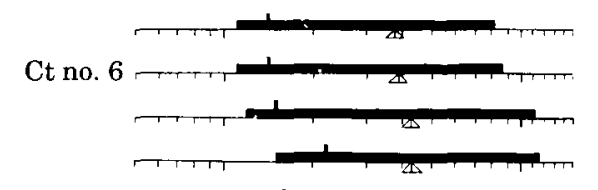

Ct no. 8

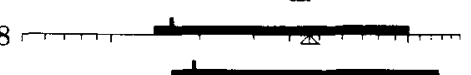

Ct no. 2
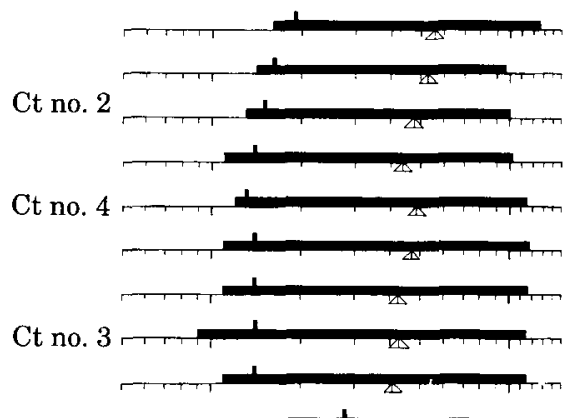

Cr no. 3

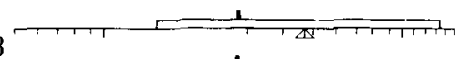

$5 \quad 10$
The two species displayed similar ranges of inter-discharge intervals, as best seen in statistical distributions or histograms, from 9 to $16 \mathrm{~ms}$ as the lower and from 80 to $140 \mathrm{~ms}$ as the upper boundary, not taking into account isolated 'stray' intervals on the right side of the histograms (for examples, see Fig. 2). The histograms of both species had only one clear, prominent peak (or mode, which is the interval of most frequent occurrence), but those of $C$.tamandua had their modes (15-16 ms) very close to the shortest interval of a distribution. Therefore, the C. tamandua histograms had a long tail of longer intervals and were heavily skewed to the right; quite often there were small secondary peaks or broad 'shoulder' regions. By contrast, the C. rhynchophorus histograms had their modes (26-28 ms) nearer to the centre of a histogram, although they never quite reached it. Therefore, they were more bell-shaped: both long and short intervals were rare.

The skewness of a histogram was characterized by the difference between the pulse interval of the mean discharge rate (for that specific histogram) and the mode (Fig. 3). The average

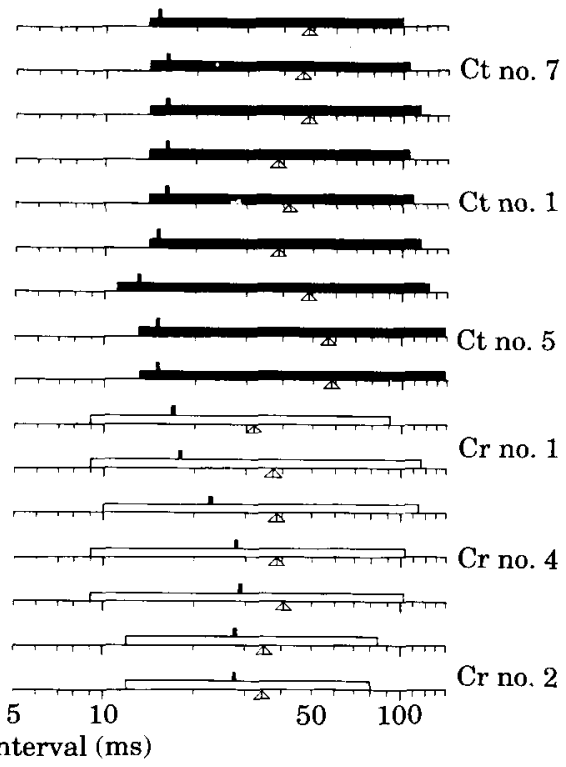

Figure 3. Diagrammatic representations of inter-discharge interval histograms, as shown in Fig. 2, in C. tamandua $(\mathrm{Ct}, \boldsymbol{)})$ and $C$. rhynchophorus $(\mathrm{Cr}, \square)$. A horizontal bar shows the range of each histogram and its mode as a 'spike' on top of it (on a logarithmic scale in ms). Note difference between a histogram mode and the interval corresponding to the mean pulse rate (arrow-heads below abscissae). Two or three samples per fish as observed on different nights. The average number of inter-discharge intervals sampled per distribution was $28463.5 \pm$ SE $980 \cdot 4$ pulses $(N=32)$. 

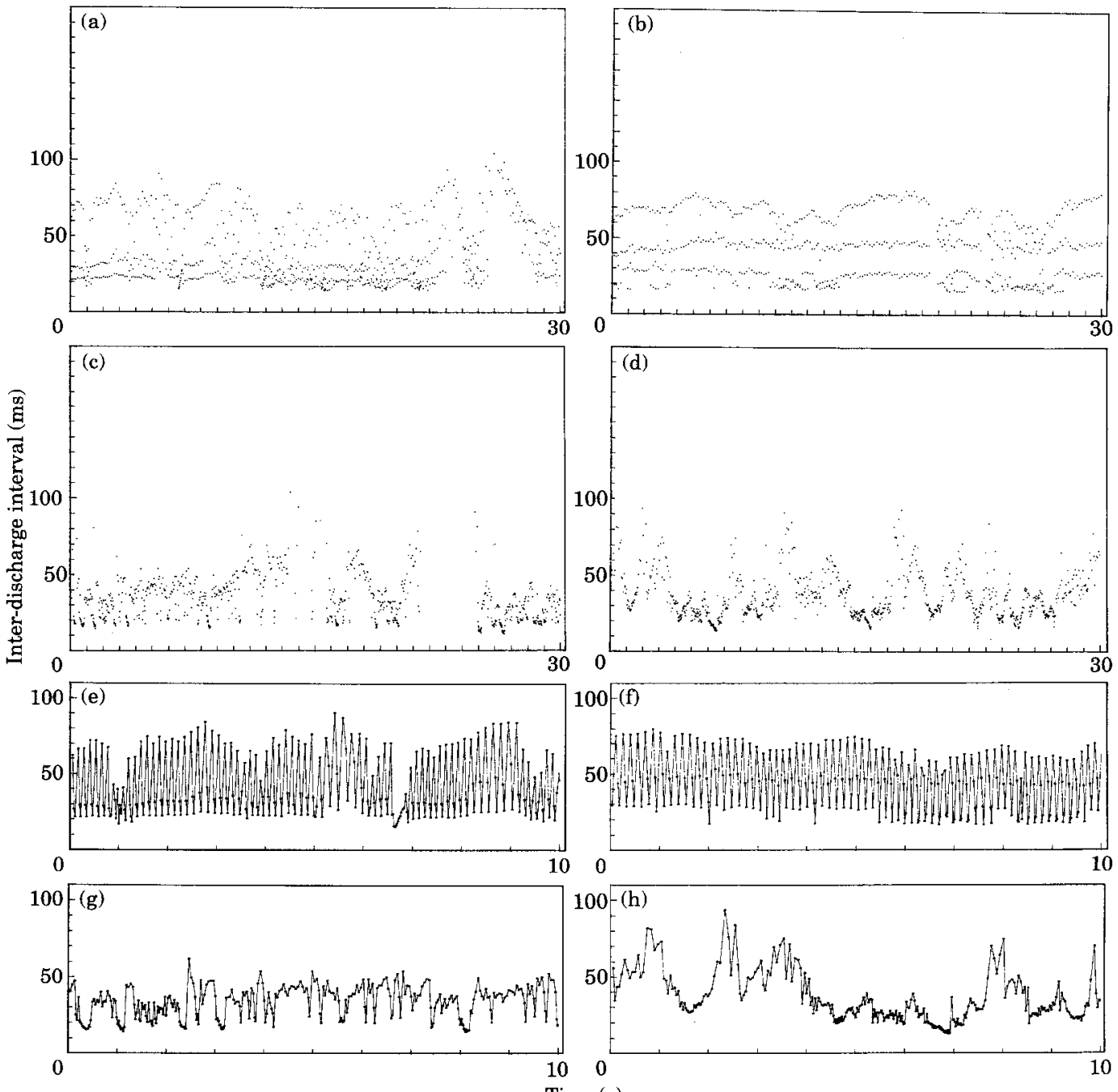

Figure 4. Sequences of inter-discharge intervals in (a) and (e) C. tamandua number 1, (b) and (f) C. tamandua number 8 , (c) and (g) C. rhynchophorus number 1, and (d) and (h) C. rhynchophorus number 2, during their nocturnal activity phase. Each set of four plots shows sections of the four stimulus patterns used for playback in preference tests. Each point is one interval. (a-d) Note the broad range of intervals displayed at almost any time in the two $C$. tamandua, while the interval durations in the $C$. rhynchophorus records follow trends with a fairly strong tendency for bursts. (e-h) Finer time resolution plots to show sequences of adjacent intervals which are connected by lines; otherwise like (a-d).

difference was significantly greater (by a factor of 2) in C. tamandua than in C. rhynchophorus histograms: 30.5 versus $14.5 \mathrm{~ms}$, respectively (Table I).

The sequences of inter-discharge intervals, although quite variable, differed in a characteristic way between the two species (Fig. 4). In all
C. tamandua there was a strong tendency to step through a sequence of three intervals of strongly contrasting durations: a long interval of $60-80 \mathrm{~ms}$ was followed by an intermediate one $(40-50 \mathrm{~ms})$ which was followed by a short one $(15-30 \mathrm{~ms})$; this three-interval sequence was sometimes repeated for many seconds without 
Table II. Individual preference scores ( $\vec{X} \pm \mathrm{SE}$; time, in s, spent within $20 \mathrm{~cm}$ of the dipole) for four $C$. rhynchophorus as experimental subjects, simultaneously stimulated with two pulse interval patterns, one conspecific $(N=2)$, the other from $C$. tamandua $(N=2)$

\begin{tabular}{lrrrc}
\hline $\begin{array}{l}\text { Experimental subject: } \\
\text { C. rhynchophorus }\end{array}$ & C. tamandua & C. rhynchophorus & $P^{*}$ & $\begin{array}{c}\text { No. of } \\
\text { replications }\end{array}$ \\
\hline No. 1 & $8.315 \pm 2.210$ & $18 \cdot 728 \pm 4.230$ & $\begin{array}{l}0.0012 \\
d f=22\end{array}$ & 23 \\
No. 2 & $27.568 \pm 7.204$ & $45 \cdot 182 \pm 10 \cdot 100$ & $\begin{array}{l}0 \cdot 0022 \\
d f=21\end{array}$ & 22 \\
No. 3 & $47.861 \pm 12.778$ & $62 \cdot 500 \pm 11 \cdot 378$ & $\begin{array}{l}0 \cdot 0030 \\
d f=8\end{array}$ & 9 \\
No. 4 & $83.273 \pm 4.597$ & $95 \cdot 727 \pm 4.480$ & $\begin{array}{l}0.0329 \\
d f=10\end{array}$ & 11
\end{tabular}

*One-tailed paired $t$-test.

interruption. As can be seen from Fig. 4, in different fish the intermediate interval may also be closer to the short interval than given in the above example.

The discharge interval sequences of C.rhynchophorus are more difficult to describe. Sometimes there was also a tendency for interval duration to alternate, but this concerned long or intermediate intervals rather than short ones, while the magnitude of the steps was also smaller. In general, the discharge intervals followed a trend of either increasing or decreasing duration for several seconds, rather often interrupted by brief bursts.

The reason for the skewed histograms in C. tamandua was the strong tendency for interval duration to alternate: the shortest category of intervals clearly occurred most often. The absence of a clear second mode in the interval histogram of C.tamandua was due to the 'smear' of the long intervals in an alternating sequence: their variation was enormous (unlike that observed in Gnathonemus petersii during agonistic behaviour where two peaks do occur in the interval histogram; Kramer \& Bauer 1976). In contrast to C. tamandua, the shortest category of intervals was much rarer in C. rhynchophorus, intermediate intervals occurring most frequently, resulting in almost symmetrical histograms.

\section{Playback Experiments}

Campylomormyrus rhynchophorus

On the onset of the simultaneous playback of two pulse interval patterns presented via two dipoles, one pattern previously recorded from a conspecific $C$. rhynchophorus and the other from a C. tamandua, fish often hesitated to leave their central porous pot for a considerable time during a trial. In most cases the fish finally swam to one of the two dipoles positioned at opposite ends of the experimental aquarium, and occasionally changed sides. They either kept in close contact with the dipole, attacked it with their mouths, or gave the dipole strong, lateral tail beats.

The times fish stayed in the vicinity $(20 \mathrm{~cm})$ of a dipole differed between the playback patterns: as expected, the attraction from conspecific playback patterns was significantly greater than that of C. tamandua patterns in all fish (Table II). Even fish number 3 with the extremely long EOD made no exception; this is additional support for its classification as a C. rhynchophorus on anatomical grounds (see Methods).

\section{Campylomormyrus tamandua}

The behaviour of the C. tamandua was very similar to that of the C. rhynchophorus except for three specimens which did not leave their central shelters and thus were excluded from the study. However, the expectation that the remaining five C. tamandua might prefer conspecific playback patterns rather than heterospecific ones, similar to the behaviour observed in C. rhynchophorus, was clearly not borne out by the results; therefore, one-tailed significance tests were inappropriate (and two-tailed tests used instead). The results were inconclusive in four out of the five C. tamandua (Table III); fish number 2 even appeared to discriminate against its own species' 
Table III. Individual preference scores ( $\bar{X} \pm \mathrm{SE}$; time, in s, spent within $20 \mathrm{~cm}$ of the dipole) for five C. tamandua as experimental subjects, simultaneously stimulated with two pulse interval patterns, one conspecific $(N=2)$, the other from $C$. rhynchophorus $(N=2)$

\begin{tabular}{lrrrc}
\hline $\begin{array}{l}\text { Experimental subject: } \\
\text { C. tamandua }\end{array}$ & C. rhynchophorus & C. tamandua & $P^{*}$ & $\begin{array}{c}\text { No. of } \\
\text { replications }\end{array}$ \\
\hline No. 1 & $77.989 \pm 4.611$ & $78.065 \pm 8.790$ & $\begin{array}{l}0.9926 \\
d f=22\end{array}$ & 23 \\
No. 2 & $101.83 \pm 11.791$ & $80.567 \pm 6.116$ & $\begin{array}{l}0.0213 \\
d f=14\end{array}$ & 15 \\
& & & & \\
No. 3 & $87.583 \pm 7.244$ & $95.389 \pm 7.545$ & $\begin{array}{l}0.4105 \\
d f=17\end{array}$ & 18 \\
No. 4 & $117.161 \pm 18.860$ & $112.857 \pm 12.480$ & $\begin{array}{l}0.8795 \\
d f=13\end{array}$ & 14 \\
No. 5 & $117.08 \pm 21.039$ & $123.44 \pm 15.402$ & 0.8222 & 13 \\
& & & $d f=12$ & \\
\hline
\end{tabular}

*Two-tailed paired $t$-test.

playback patterns because the preference score for the $C$. rhynchophorus patterns was significantly higher $(P<0.05)$.

This paradoxical result might, however, be due to the very weak response (perhaps a kind of 'dislike'?) of this fish regarding one conspecific playback pattern; there was very little difference between the scores for the alternative pattern and the $C$. rhynchophorus patterns. Therefore, fish number 2 appeared to discriminate between conspecific patterns rather than between the playback patterns from its own species and those from C. rhynchophorus. Neither conspecific pattern had been recorded from fish number 2 .

\section{DISCUSSION}

The waveform of an EOD is species-characteristic (Lissmann 1958; Hopkins 1981) and individually variable (for reviews see Hopkins 1986; Kramer $1990 \mathrm{~b}, 1994)$. Some authors consider sexually dimorphic differences in a species' EOD waveform rather than in its sequence of pulse intervals as the basis for mate recognition (Hopkins \& Bass 1981); others consider the sequence of pulse intervals to be of prime importance in mormyrid communication, and regard the EOD waveform variability as the sensory basis for individual rather than mate recognition (Graff \& Kramer 1989, 1992). Some of these discrepancies may be due to species differences within the large family of Mormyridae (almost 200 species).
In the species studied best in this regard, Pollimyrus isidori, initial mate recognition occurs via the male's sound production (Crawford et al. 1986; Bratton \& Kramer 1989), while the sequence of pulse intervals is important during subsequent courtship and spawning (Bratton \& Kramer 1989; Crawford 1991). The two latter studies also showed that the EOD waveform was not a factor in mate recognition and pair formation.

On different nights certain individuals differed in their mean discharge rates by up to 5 pulses/s. This is because we rarely observed uniform, moderate swimming in our fish; sequences of slow or more rapid swimming, sudden accelerations and stops, probing, hovering, etc. were usual. In Pollimyrus isidori these different types of swimming behaviour were also accompanied by markedly different discharge patterns (Bratton \& Kramer 1989). Because of the rather great variability of discharge activity (even in the same fish), the discharge sequences from two individuals of each species were randomly chosen for the stimulation experiments.

To study the significance of pulse interval sequences for species recognition, the natural EOD waveform was replaced by a square-wave pulse in the present experiments. The sequences of discharge intervals accompanying nocturnal locomotory activity were clearly different for the two Campylomormyrus species: C. tamandua displayed long sequences of a rhythmic three-interval pattern marked by strong contrasts in interval duration, while in C. rhynchophorus there were 
trends comprising longer sequences of intervals more similar in duration, often interrupted by brief bursts. There were also statistically significant differences in mean discharge rate and in the skewness of interval histograms. The $C$. tamandua discharge activity showed clear 'micro-patterns' as suggested by Kramer \& Lücker (1990): interval sequences that were both short and characteristic. Pollimyrus isidori which discriminates a pulse rate change as small as $2 \%$ is the only species tested for its time interval resolution (Kramer \& Heinrich 1990).

It is tempting to speculate that during sympatric evolution character displacement has acted on the two species' discharge interval patterns which are so markedly different, while their EOD waveforms are so surprisingly similar (except the EOD of C. rhynchophorus number 3 which was exceedingly long). Whether the two discharge durations in C. rhynchophorus represent a sexual dimorphism or a polymorphism (Moller \& Brown 1990) is impossible to ascertain at present.

In the playback experiments the four C. rhynchophorus showed a significant preference for their conspecific patterns while this could not be demonstrated in the C. tamandua (Tables II and III). The behaviour of the C. rhynchophorus corresponded well to that shown by Petrocephalus bovei in similar preference experiments involving a choice between two pulse patterns, recorded from members of their own species and from those of other mormyrid genera (Lücker 1983; Kramer \& Lücker 1990). Even though totally unnatural pulse waveforms were used for playback in both studies, conspecific pulse interval patterns were discriminated from other species' patterns. These patterns evoked association behaviour and also various forms of agonistic behaviour in the present study. It is possible that in our experiments the differences would have been still more pronounced had the natural EOD waveforms been used instead of a square-wave pulse. Mutual discrimination of the two species' EOD waveforms may be assumed because of $P$. isidori's exceedingly high sensitivity to small differences in conspecific EOD waveforms

- (Graff \& Kramer 1992).

The non-discriminating behaviour of the C. tamandua is difficult to explain given the pronounced differences in interval patterns which the $C$, rhynchophorus clearly noticed. Rather than being unable to detect the difference we believe the C. tamandua might not have shown discriminating behaviour because of a propensity to join mixedspecies groups. Such groups have been reported several times from the field (for reviews see Hopkins 1986; Kramer 1990b), and are especially likely in juveniles. Although our C. tamandua and $C$. rhynchophorus were of similar size, the C. tamandua were clearly juveniles while the C. rhynchophorus were not (see Methods). The maximum size of C. tamandua is more than twice that reported for C. rhynchophorus; in addition, even our biggest specimen of $C$. tamandua still had the characteristic juvenile coloration. In contrast to the C.tamandua, our C.rhynchophorus of about half maximal size were probably sexually mature or close to sexual maturity. This is suggested by a study on Hippopotamyrus pictus which were sexually mature at somewhat less than half maximum size ( $12 \mathrm{~cm}$ length versus $26 \mathrm{~cm}$; Blake 1977).

Sexually mature fish are much more likely to discriminate against members of other species than are immatures. Therefore, we believe the present study supports the notion that one of the functions of the inter-discharge interval code of communication in mormyrids is species recognition, although fish may not show their sensory capabilities during all stages of their lives (especially when immature). The relatively more mature C. rhynchophorus were discriminating pulse interval patterns recorded during the fish's nocturnal active phase when species recognition is especially important for group cohesion or finding a mate.

\section{ACKNOWLEDGMENTS}

Expert help with the electronic apparatus from D. Weymann is gratefully acknowledged. We were supported financially by the Deutsche Forschungsgemeinschaft (Sonderforschungsbereich 4, Teilprojekt H1 to B.K.).

\section{REFERENCES}

Bastian, J. 1990. Electroreception. In: Comparative Perception, Vol. II: Complex Signals (Ed. by W. C. Stebbins \& M. H. Berkeley), pp. 35 89. New York: John Wiley.

Blake, B. F. 1977. Aspects of the reproductive biology of Hippopotamyrus pictus from lake Kainji, with notes on four other mormyrid species. J. Fish Biol., 11, $437-445$. 
Bratton, B. O. \& Kramer, B. 1989. Patterns of the electric organ discharge during courtship and spawning in the mormyrid Pollimyrus isidori. Behav. Ecol. Sociobiol., 24, 349-368.

Cochran, W. G. \& Cox, G. M. 1957. Experimental Designs. 2nd edn. New York: John Wiley.

Crawford, J. D. 1991. Sex recognition by electric cues in a sound-producing mormyrid fish, Pollimyrus isidori. Brain Behav. Evol., 38, 20-38.

Crawford, J. D., Hagedorn, M. \& Hopkins, C. D. 1986. Acoustic communication in an electric fish, Pollimyrus isidori (Mormyridae). J. comp. Physiol., 159, 297-310.

Daget, J. \& Durand, J. R. 1981. Poissons. In: Flore et Faune Aquatiques de l'Afrique Sahélo-soudanienne, Vol. 2 (Ed. by J. R. Durand \& C. Lévêque), pp. 687-771. Paris: ORSTOM.

Gosse, J.-P. 1984. Mormyriformes. In: Check-list of the Freshwater Fishes of Africa (Ed. by J. Daget, J.-P. Gosse \& D. F. E. Thys van den Audenaerde), pp. 63-124. Bondy (France)/Tervuren (Belgium): ORSTOM/MRAC.

Graff, C. \& Kramer, B. 1989. Conditioned discrimination of the E.O.D. waveform by Pollimyrus isidori and Gnathonemus petersii. In: Neural Mechanisms of Behavior (Ed. by J. Erber, R. Menzel, H. J. Pflüger \& D. Todt), page 94. Stuttgart: Georg Thieme Verlag.

Graff, C. \& Kramer, B. 1992. Trained weakly-electric fishes Pollimyrus isidori and Gnathonemus petersii (Mormyridae, Teleostei) discriminate between waveforms of electric pulse discharges. Ethology, 90, 279292.

Hopkins, C. D. 1981. On the diversity of electric signals in a community of mormyrid electric fish in West Africa. Am. Zool, 21, 211-222.

Hopkins, C. D. 1986. Behavior of mormyridae. In: Electroreception (Ed. by T. H. Bullock \& W. Heiligenberg), pp. 527-576. New York: John Wiley.

Hopkins, C. D. 1988. Neuroethology of electric communication. A. Rev. Neurosci., 11, 497-535.

Hopkins, C. D. \& Bass, A. H. 1981. Temporal coding of species recognition signals in an electric fish. Science, 212, 85-87.

Kramer, B. 1974. Electric organ discharge interaction during interspecific agonistic behaviour in freely swimming mormyrid fish. A method to evaluate two (or more) simultaneous time series of events with a digital analyser. J. comp. Physiol., 93, 203-235.

Kramer, B. 1990a. Sexual signals in electric fishes. Trends Ecol. Evol, 5, 247-250.

Kramer, B. 1990b. Electrocommunication in Teleost Fishes: Behavior and Experiments. Berlin: SpringerVerlag.

Kramer, B. 1994. Communication behaviour and sensory mechanisms in weakly electric fishes. In: Advances in the Study of Behavior, Vol. 23 (Ed. by P. J. B. Slater, J. S. Rosenblatt, C. T. Snowdon \& M. Milinski), pp. 233-270. San Diego: Academic Press.

Kramer, B. \& Bauer, R. 1976. Agonistic behaviour and electric signalling in a mormyrid fish, Gnathonemus petersii. Behav. Ecol. Sociobiol., 1, 45-61.
Kramer, B. \& Heinrich, U. 1990. Discrimination of inter-pulse intervals. In: Electrocommunication in Teleost Fishes: Behavior and Experiments (Ed. by B. Kramer), pp. 170-177. Berlin: Springer-Verlag.

Kramer, B. \& Kuhn, B. 1993. Electric signalling and impedance matching in a variable environment: the electric organ of a mormyrid fish actively adapts to changes in water conductivity. Naturwissenschaften, 80, 43-46.

Kramer, B. \& Lücker, H. 1990. Species recognition by EOD interval pattern. In: Electrocommunication in Teleost Fishes: Behavior and Experiments (Ed. by B. Kramer), pp. 157-170. Berlin: Springer-Verlag.

Kramer, B. \& Weymann, D. 1987. A microprocessor system for the digital synthesis of pulsed or continuous discharges of electric fish (or animal vocalizations). Behav. Brain Res., 23, 167-174.

Kroodsma, D. E. 1989. Suggested experimental designs for song playback. Anim. Behav., 37, 600-609.

Lèvêque, C. \& Paugy, D. 1984. Guide des Poissons d'Eau Douce de la Zone du Programme de Lutte contre l'Onchocercose en Afrique de l'Ouest. Paris: Convention ORSTOM-OMS.

Lévêque, C., Paugy, D. \& Teugels, G. G. 1990. Faune des Poissons d'Eaux Douces et Saumâtres de l'Afrique de l'Ouest, Vol. 1. Tervuren (Belgium)/Paris (France): Musée Royal de l'Afrique Centrale/Editions de l'ORSTOM.

Lissmann, H. W. 1958. On the function and evolution of electric organs in fish. J. exp. Biol, 35, 156-191.

Lücker, H. 1982. Untersuchungen zur intraspezifischen Elektrokommunikation mittels der Latenzbeziehungen und zur interspezifischen Elektrokommunikation mittels der art-und aktivitätsspezifischen Entladungsmuster bei Pollimyrus isidori (Cuv. \& Val.) und Petrocephalus bovei (Cuv. \& Val.). Ph.D. thesis, University of Konstanz.

Lücker, H. 1983. Species-specific discharge rhythms in mormyrids as a mechanism for species identification (in German). Verh. dt zool. Ges., 76, 195.

Moller, P. 1976. Electric signals and schooling behavior in a weakly electric fish, Marcusenius cyprinoides (Mormyriformes). Science, 193, 697-699.

Moller, P. 1980. Electroreception and the behaviour of mormyrid electric fish. Trends Neurosci, 3, 105-109.

Moller, P. \& Brown, B. 1990. Meristic characters and electric organ discharge of Mormyrops curviceps Roman (Teleostei: Mormyridae) from the Moa river, Sierra Leone, West Africa. Copeia, 1990, 1031-1040.

Moller, P. \& Serrier, J. 1986. Species recognition in mormyrid weakly electric fish. Anim. Behav., 34, 333-339.

Moller, P., Serrier, J., Belbenoit, P. \& Push, S. 1979. Notes on ethology and ecology of the Swashi River Mormyrids (Lake Kainji, Nigeria). Behav. Ecol. Sociobiol., 4, 357-368.

Moller, P., Serrier, J., Squire, A. \& Boudinot, M. 1982. Social spacing in the mormyrid fish Gnathonemus petersii (Pisces): a multisensory approach. Anim. Behav., 30, 641-650.

Neave, H. R. \& Worthington, P. L. 1988. Distributionfree Tests. London: Unwin Hyman. 
Poll, M., Gosse, J.-P. \& Orts, S. 1982. Le genre Campylomormyrus Bleeker, 1874, étude systématique et description d'une espèce nouvelle (Pisces, Mormyridae). Bull. Inst. r. Sci. nat. Belg. Biol., 54, 1-34.

Sachs, L. 1984. Angewandte Statistik. 6th edn. Berlin: Springer-Verlag.
Siegel, S. \& Castellan, N. J., Jr. 1988. Nonparametric Statistics for the Behavioral Sciences. 2nd edn. New York: McGraw-Hill.

Teyssèdre, C. \& Moller, P. 1982. The optomotor response in weak electric fish: can they see? $Z$. Tierpsychol, 60, 306-312. 